\title{
Thoracic and Lumbosacral Spinal Cord Ependymal Tumor
}

National Cancer Institute

\section{Source}

National Cancer Institute. Thoracic and Lumbosacral Spinal Cord Ependymal Tumor. NCI

Thesaurus. Code C131606.

An ependymal tumor affecting the spinal cord in the thoracic and lumbosacral regions. 